\title{
Towards Biocatalytic Reactions Under Continuous Flow Conditions
}

\author{
Marcella C. Flores, Ivaldo I. Junior, Felipe K. Sutili, Ivana C. R. Leal, Leandro S. M. e \\ Miranda, Rodrigo O. M. A. de Souza
}

Insert the address(es) here (Arial 10)

*rodrigosouza@iq.ufrj.br:

Keywords: flow chemistry, biocatalysis, lipase

\section{INTRODUCTION}

For industrial purpose, the continuous flow system is preferred to batch reactors due to its greater process control, high productivity and improvement of quality/purity and yield. Several types of reactor can be used in continuous operation, among those reactors, packed bed reactors (PBR) are the most popular due to its high efficiency, low cost and ease of construction, operation and maintenance.

In this work we have optimized a biocatalytic continuous flow processes with packed bed reactors in three different approaches: 1) esterification reaction between solketal and stearic acid using response surface methodology (RSM) in a laboratory setting; 2) esterification reaction between solketal and acidic residue of food industry, using response surface methodology (RSM) in a laboratory setting; 3) partial hydrolysis of Palm Oil to the production of diacylglycerols.

\section{RESULTS AND DISCUSSION}

First we have developed a continuous flow process to the solketal esterification with the assistance of the surface response methodology (RSM) and stearic acid leading to the desired product in excellent conversions and short reaction time. The optimized process also allows the use of palmitc acid with high conversions while the use of unsaturated fatty acids or short chain fatty acids leads to a significant reduction on conversion (Table 1)

\begin{tabular}{ccc}
\hline Entry & Fatty Acid & Conversion $(\boldsymbol{\%})^{\mathbf{a}}$ \\
\hline 1 & Stearic & 95 \\
2 & Palmitic & 97 \\
3 & Oleic & 40 \\
4 & Myristic & 32 \\
5 & Lauric & 41 \\
\hline
\end{tabular}

Table 1: Esterification of solketal with different fatty acids sources at $60^{\circ} \mathrm{C}$ and flow rate of $0.4 \mathrm{ml} / \mathrm{min}$.
Then we have performed the partial hydrolysis of palm oil catalyzed by lipases under microwave irradiation in short reaction times and moderated yields. These results were used as starting points to the development of a conventional heating flow process for DAG production with packed bed reactors. The results obtained in flow mode were better than those under microwave irradiation and allowed us to produce $128 \mathrm{~g}$ of DAG in $24 \mathrm{~h}$. The rate flow is an important parameter to get the best yield on the partial hydrolysis of palm oil and the oil must be diluted in order to avoid blocking the system by crystallization.

Another procedure also studied by our group was the reaction between solketal and acidic residue from Palm Oil industry. The main objective was synthesizing emulsifiers from waste material. The results obtained shows that moderate to good results can be achieved under mild conditions and short reaction time (Table 2).

\begin{tabular}{cccc}
\hline Entry & Flow Rate & {$[\mathrm{C}]$} & Conversion (\%) \\
\hline 1 & 0.4 & $72 \mathrm{mM}$ & 56 \\
2 & 0.4 & $72 \mathrm{mM}$ & 53 \\
3 & 0.4 & $91 \mathrm{mM}$ & 76 \\
\hline
\end{tabular}

Table 2: Esterification of acidic residue from Palm Oil industry with solketal

\section{CONCLUSION}

In conclusion we have developed different approaches for emulsifiers' production under continuous flow conditions.

\section{ACKNOWLEDGEMENTS}

We thank CAPES, CNPq, FAPERJ and FINEP for financial support and Agropalma for Palm Oil sample.

\section{REFERENCES}

1 P. Watts, C. Wiles Eur. J. Org. Chem. 2008, 10, 1655-1671.

${ }^{1}$ A. Kirschning, S. Ceylan, J. Wegner Chem. Comm. 2011, 47, 4583 -

4592 